\title{
pÿ Being one of the boys : perspectives from female forest industry leaders on gender diversity and the future of Nordic forest-based bioeconomy
}

\author{
Baublyte, Gintare
}

2019-08-18

pÿBaublyte , G , Korhonen , J , D'Amato , D \& Toppinen , A 2019 , ' Being one of the boys : perspectives from female forest industry leaders on gender diversity and the future of Nordic forest-based bioeconomy ' , Scandinavian Journal of Forest Research , vol. 34 , no. 6 , pp. 521-528 . https://doi.org/10.1080/02827581.2019.1598484

http://hdl.handle.net/10138/314131

https://doi.org/10.1080/02827581.2019.1598484

cc_by_nc_nd

acceptedVersion

Downloaded from Helda, University of Helsinki institutional repository.

This is an electronic reprint of the original article.

This reprint may differ from the original in pagination and typographic detail.

Please cite the original version. 
4

6

\title{
industry leaders on gender diversity and the future of Nordic
}

\section{forest-based bioeconomy}

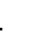

\author{
Baublyte, G. ${ }^{1}$, Korhonen, J. ${ }^{1,2}, D^{\prime}$ Amato, D. ${ }^{1,2} \&$ Toppinen, A. ${ }^{1,2}$ \\ ${ }^{1}$ University of Helsinki, Department of Forest Sciences, Latokartanonkaari 7, FI-00014, \\ Helsinki, Finland \\ ${ }^{2}$ Helsinki Institute of Sustainability Science (HELSUS) \\ ,*Corresponding author anne.toppinen@ helsinki.fi
}

\begin{abstract}
Women working in the Nordic forest sector are underrepresented in top leadership positions, despite the female share increasing in higher education programs. Little research exists on this niche actor group in the forest sector context. To fill this gap, we assess perceptions of female leaders on the state of gender diversity in the Nordic forest industry, on the future of the forest sector in the bioeconomy, and on the potential contribution the Nordic forest industry can make to empower women, as promoted by the UN Sustainable Development Goals. An elite interviewing strategy was used to engage female leaders working at the top management level of seven Finnish and Swedish forest companies. According to our results, adapting to "being one of the boys" appears to persist as a norm for female leaders in this masculine industry field. Participants believed that their influence on the industry's sustainability agenda comes from being in a senior management position, and is not a gender-related aspect. We conclude that the ability of the Nordic forest industry to adapt to strategic renewal into the bioeconomy will require a more diverse company culture, which is not solely gender-based and is fostered at all organizational levels.
\end{abstract}

Keywords: forest sector; bioeconomy; gender diversity; career roles; sustainability

\section{Introduction}

An aging workforce, demand for industry renewal, and rising social and environmental sustainability challenges demand a fundamental transformation of the forest sector. Part 
of this transformation relates to diversity in company management, including gender diversity. Women are still underrepresented in the top leadership positions of the Nordic forest sector, despite high representation in higher education programs (Johansson and Ringblom 2017). Also, female members represent a $16 \%$ share in both the boards of directors and top management teams in the global top 100 pulp and paper companies (Hansen et al. 2016). Positive changes in terms of increasing diversity in decision-making processes have occurred during past decades, but unequal use of power in the sector, or in society in general, may still compound unnecessary gender stereotypes.

Gender inequality and women empowerment is high in the political agenda globally, being one of the UN Sustainable Development Goals (SDGs) for 2030, (SDG no. 5). Moreover, gender issues, such as lack of professional identity among women in the forest sector (Appelstrand and Lidestav 2015), may prevent the most skilled individuals access to management positions (Holmgren and Arora-Jonsson 2015), thus also hampering the renewal and transformation of the sector.

The existing evidence base related to gendered culture deriving from diversity management in the forest sector is surprisingly scarce. Lidestav and Sjölander (2007) analyzed Swedish forestry professionals, and Appelstrand and Lidestav (2015) focused on female entrepreneurs. In addition, a few forest ownership-focused studies exist (e.g. Umaerus et al. 2013; Follo et al. 2017), but very limited research has been conducted on gender aspects in the forest industry. An exception is Hansen et al. (2016), who modeled the effect of an increased female proportion in the top management level of the global pulp and paper industry, and found it to have a small but positive effect on company-level performance. Moreover, the role of workforce diversity and gender issues as a part of the core business strategy towards a more sustainable forest-based bioeconomy - a dominant concept in the current political and academic discussion on sustainability - has received little to no attention (e.g. Li and Toppinen 2011; Hansen 2016).

In our study, we explore the perceptions of female leaders working in the Nordic forest industry regarding the state and forms of existing gendered culture that impact their careers at the workplace. We inquire about female leaders' perspectives on the future of the forest sector in the bioeconomy, and about the potential contribution of female leadership in the decision-making process towards increased sustainability of the Nordic forest industry, in light of the Global Agenda 2030 goals. This explorative study offers 

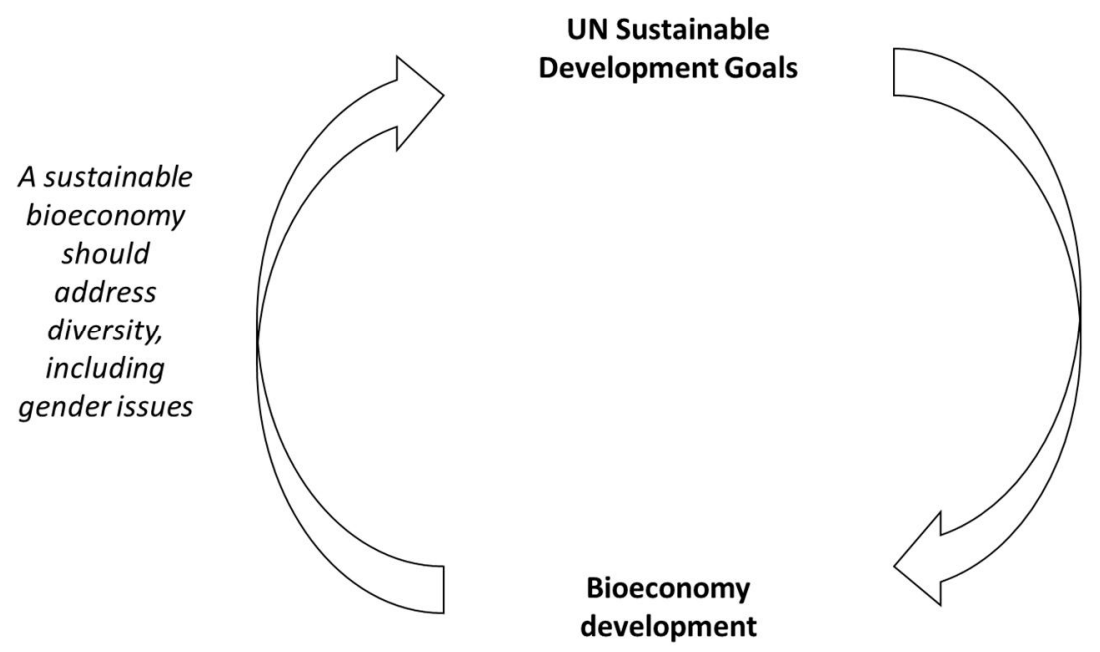

Figure 1. The relationship between gender diversity, sustainability, and bioeconomy

80 development.

\section{Conceptual background}

\section{Gendered culture and the forest sector}

The structural problems related to female representation in labor markets generally include a pay gap between men and women in similar positions, and generally lower salary levels in female-dominant sectors (Blau and Kahn 2017). The creation of gendered

88 practices that eventually set the norms in an organization can be an obstacle for 89 institutional change, as people presenting the non-dominant gender may feel their 90 competence and authority diminished or questioned.

91 Diversity in top management positions, including gender diversity, tends to have positive 92 effects on firm performance (Perrault 2015). The business benefits gained through a 93 higher degree of diversity in top management may include improved financial 94 performance or strategic benefits such as better compliance with the ethical and social 95 standards of a company. This may indirectly raise company value (Isidro et al. 2014) or 96 result in higher sustainability ratings (Bear et al. 2010), fostering stakeholders' trust in 
97 the company (Perrault 2015). Enhanced corporate reputation and employee attractiveness

98 (Kakabadse et al. 2015) are other commonly mentioned benefits. The majority of large-

99 scale companies in the Nordic region tend to incorporate certain gender balancing

100 elements embedded in their code of conduct or as a part of their sustainability programs.

101 The gender equality aspect is also covered in the national implementation plans of both

102 Finland and Sweden for the SDGs of Agenda 2030. Certain forest companies also

103 explicitly acknowledge gender equality and women's empowerment, but SDG 5 is also

104 integral to all dimensions of inclusive and sustainable development.

105 Diversity may naturally also have adverse effects on company performance, for example

106 via increased decision-making costs due to reoccurring conflicts and general friction

107 between board members (Adams et al. 2015), but overall, the available literature appears

108 to highlight a greater range of positive than negative outcomes. In addition, further

109 evidence shows that a minimum threshold may exist in terms of diversity based on

110 representation of different sexes, as Post et al. (2011) suggest that having as few as three

111 or more females on a board of directors can positively influence a company's

112 environmental performance.

113 In reviewing forestry-related diversity management literature focusing on the rate of

114 female and male representation, Baublyte (2017) identified several barriers that women

115 may experience in their career paths before reaching top leadership level. These barriers

116 range from stereotypes and twisted role models to industry culture and social policy -

117 related aspects. One issue is the tokenism problem, which arises when females are hired

118 to only improve a company's female-male ratio, to give the impression of better equality

119 within the workforce. Token females often feel excluded from the rest of the management

120 group, which concurrently lacks support and respect for the token member. Thus, despite

121 females potentially possessing strengths to improve corporate sustainability and the

122 decision-making process, just having token women is not enough (Bear et al., 2010).

123 Another interesting aspect is the "Queen Bee syndrome", a situation where senior female

124 leaders who have reached the top, demonstrate their preferences for men instead of

125 helping other females advance their careers in male-dominant firms and fields (Derks et

126 al. 2011).

127 Holmgren and Arora-Jonsson (2015) argue that gender equality in the forest sector has

128 turned into an issue of individuals' opportunities to work and make business, rather than 
an opportunity to disturb the established and structural power relations in decision-

130 making. While the most serious gender-related human problems most likely occur outside 131 the Nordic regions, the Nordics would also benefit from improvements, despite generally 132 being known as prime examples of gender equality. Johansson et al. (2018) recently 133 documented the prevailing forms of gendered culture regarding sexual harassment in the 134 context of the Swedish forest sector, suggesting further research on the actual 135 mechanisms that allow sexist behavior, both at the workplace and in education.

Bioeconomy and sustainability

138 The bioeconomy is among the currently dominant concepts for informing and shaping

139 pathways for global sustainability transformations (D'Amato et al., 2017). It proposes to 140 substitute current fossil-based industrial inputs (materials, chemicals, energy) with 141 renewable biological resources (Kleinschmit et al. 2014; Pfau et al. 2014; Bugge et al. 142 2016), as Table 1 illustrates. Knowledge and biotechnology -based innovations are key 143 elements, especially regarding shifts from lower value products/services (e.g. bioenergy, 144 fiber) to higher value ones (e.g. bio-based materials, chemicals, and pharmaceuticals).

145 The forest sector has a central role in the bioeconomy as both a provider of biomass, and 146 as a manufacturer of higher-value products (Kleinschmit et al. 2014; Roos and Stendahl 147 2015). In fact, despite the bioeconomy appearing to be an emerging concept in the context 148 of corporate sustainability across various sectors, companies in the forest sector are 149 actively adopting it for communicating sustainability issues (D’Amato et al. 2019).

150 According to Korhonen et al. (2018), the realization of bioeconomy ambitions hinges to 151 a great extent on the competitiveness of bio-based firms and industries, and their ability 152 to combine a more diverse knowledge base. The bioeconomy is thus supposed to 153 contribute to and benefit from the development of regional, multi-actor clusters of competences, knowledge, and technologies (Bugge et al. 2016). This is to be supported by, among other industry transformations, a sufficient level of diversity in company 156 leadership and workforce (Wolfslehner et al. 2016), including ethnic, professional, age, 157 sex and gender -related aspects. 
161 Table 1. Summary of the main visions of the bioeconomy for sustainability.

\begin{tabular}{|l|l|}
\hline $\begin{array}{l}\text { Sustainability } \\
\text { dimension }\end{array}$ & Main vision of the bioeconomy \\
\hline Economic & $\begin{array}{l}\text { New bio-based or hybrid products and services, advancements in } \\
\text { production and innovation with biotechnology; sectoral renewal and } \\
\text { inter-sectoral collaboration (Hansen 2016; Reim et al. 2018). }\end{array}$ \\
\hline Social & $\begin{array}{l}\text { Primary producer livelihoods in rural areas (forestry, agriculture, } \\
\text { fisheries); consumer or user-oriented products and services; regional, } \\
\text { multi-actor clusters of competences, knowledge, and technologies } \\
\text { (Bugge et al. 2016; Pelli et al. 2017). }\end{array}$ \\
\hline Environmental & $\begin{array}{l}\text { Substituting fossil resources with bio-based ones, possibly following } \\
\text { principles relating to sustainable sourcing, cascading use of biomass, } \\
\text { and recycling. }\end{array}$ \\
\hline
\end{tabular}

163 Several scholars and experts have pointed out the current limits of the bioeconomy as a

164 concept for forwarding environmental and social sustainability (El-Chichakli et al. 2016;

165 Kröger \& Raitio 2017; Pfau et al. 2014) (Table 1). For example, sustainable sourcing of

166 biomass and efficient resource use, including recycling and reuse, are not explicitly

167 addressed in the mainstream understanding of the bioeconomy. Scholars have thus

168 advocated a more inclusive conceptualization of the bioeconomy, which could draw from

169 related sustainability concepts (e.g. circular and green economy) (Bennich and Belyazid

170 2017; D’Amato et al. 2017, 2018; Hetemäki 2017). Mustalahti (2018) pointed out that

171 the forest sector and bioeconomy emphasize the role of industrial sectors in Finland, while

172 more discussion is needed on human rights, consumer behavior, and citizen participation.

\section{Data and methods}

175 Our initial company population was selected from a study by Hansen et al. (2016), 176 analyzing the state of female representation in the top 100 global pulp and paper 177 industries, which lists five Swedish companies (Holmen, Setra Group, Södra, Sveaskog, 
178 Svenska Cellulosa) and three Finnish forestry companies (Ahlstrom, Stora Enso, UPM-

179 Kymmene). During the research process, Ahlstrom underwent an organizational change and became a Swedish-based company Ahlstrom-Munksjö.

182 We used an elite interviewing strategy (cf. Berry 2002) to engage women working in top

183 management. As the women represent a minority at the management level, we assume

184 their views are particularly helpful for identifying traits of gendered culture in the field.

185 The interview invitations were first emailed to the intended participants. If a response was 186 not received, the selected individuals were contacted multiple times via phone or email during a seven-month period in 2017.

189 Among the identified total sample of 32 female leaders in top management teams or in 190 leadership roles of business lines, 10 were available for interviewing in person or over 191 the phone, 14 declined the request, and eight could not be reached. Respondents belonged 192 to seven different forest companies, and their professional roles varied from division

193 leadership to human resources and legal affairs (see Table 2). Drawing conclusions on 194 non-respondent bias is not possible using qualitative data, but we can note that female 195 leaders responsible for corporate communications declined more often than others when 196 comparing the set of non-respondents. This may relate to communication vice presidents 197 with non-forestry backgrounds feeling that they have no direct stake in discussing gender 198 diversity issues in the forest industry.

200 Table 2. Interviewees' area of responsibility, country of employment, and duration of the 201 interview.

\begin{tabular}{|l|l|l|c|}
\hline id & Area of responsibility & Country & $\begin{array}{l}\text { Interview } \\
\text { duration (min) }\end{array}$ \\
\hline 1 & Business division & Finland & 45 \\
\hline 2 & $\begin{array}{l}\text { Sustainability } \\
\text { management }\end{array}$ & Finland & 40 \\
\hline 3 & Human Resources & Finland & 25 \\
\hline 4 & Human Resources & Sweden & 15 \\
\hline 5 & Business division & Sweden & 20 \\
\hline 6 & Legal affairs & Sweden & 20 \\
\hline 7 & Business division & Sweden & 15 \\
\hline 8 & Business division & Sweden & 20 \\
\hline 9 & Finance & Sweden & 25 \\
\hline 10 & Business development & Sweden & 15 \\
\hline
\end{tabular}


203 Before the interviews, the interviewer researched each company to analyze gender 204 diversity in the top management, diversity programs, and company primary business 205 focus. The interviews and interview style were adjusted to match the interviewees. This 206 allowed for better understanding of the ideas expressed by the interviewees, enabling 207 better probing techniques, if necessary. Multiple sources were used to validate the 208 interviews, which helped minimize the problem of exaggeration and the possibility of 209 misunderstanding concepts (Berry 2002). Ensuring confidentiality of the interviewees' 210 identities allowed for more reliable and open communication between the interviewer and 211 interviewees.

213 The interviews were conducted during April-November 2017 in English, and they lasted 214 an average of $25 \mathrm{~min}$. The interviews were recorded with permission from the 215 participants, and the data were then transcribed and coded. Thematization was used as a 216 research method for coding the collected interview data. Firstly, we explored each 217 interviewee's perceptions concerning the state of gender roles and culture in the industry 218 and in their company strategic planning. Secondly, we focused on the future of the 219 industry, and aimed to investigate the potential of forest sector contribution to a more 220 sustainable bio-based economy.

222 Despite the above-mentioned precautions implemented to guarantee successful data 223 collection (we followed methods used in similar studies or recommended by relevant 224 literature, e.g. Gummesson 1991; D’ Amato et al. 2016), remaining limitations to our data include the following. First, internal validity of the data is dependent on the interviewees' experiences and knowledge of the study participants. As a positive side, many of our interviewed leaders had worked in the industry for many years, even several decades, and had experienced somewhat similar career paths. However, certain participants had only spent a few years working in the forest industry. Second, keeping in mind the sensitivity 230 of the topic from a highly personal perspective, it is possible that certain interviewees 231 were not entirely open about their experiences and insights despite their full confidentiality being assured. Third, due to the small number of study participants, a comparison between the two countries or across professional responsibilities is not possible, and the observed differences may still be based more on differences between 
companies rather than individuals or their home countries. Fourth, with such a small sample, it is impossible to tell how certain enablers could affect the career paths of other women in the same industry. Finally, it is impossible to know how the interviewees' careers would have differed if certain personal-level enablers or barriers had not occurred during the interviewees' way to top management.

\section{Results}

\section{Gendered culture in the top management of the Nordic forest industry}

243 The gendered culture was perceived to prevent females from having equal opportunities 244 for reaching leadership positions. According to the interviewees, women in the Nordic 245 forest industry are expected to adjust their professional image and behavior to match the standards set by male colleagues, which is likely to hinder institutional change toward true gender equality (Arora and Jonsson 2015; Appelstrand and Lidestav 2015). Adapting to "being one of the boys" appears to persist as a norm for female leaders, as illustrated by the following quote:

"I think I have not made it [gender] an issue. In that sense, I guess being one of the boys but yet a female. So I think what has helped me, I think are my leadership skills, I think I'm good with people, good with customers, but also good with [my] own people."

The inability to participate in certain social practices, such as sauna or hunting, did emerge in several interviews as an important challenge for female career development. Exclusion from social practices implies missed opportunities for social bonding, networking, and information sharing; more importantly, it means not being able to fully participate in informal decision-making processes. In the context of sauna, one interviewee expressed her position as: they would go in after me. They would go to a social event, and I would be

The observations that female leaders "age faster" than their male colleagues can be considered sexist, as one interviewee stated: "A 50-year-old lady is older than a 50-year- 
old man." The perceived difference in aging is a yet unidentified form of gendered culture

268 in the forest sector (see Johansson et al. 2018). Someone identified the lack of technical 269 forestry education background to act as an entry barrier into the field and career 270 development, as the following quote demonstrates: “...At least in Sweden, you tend to 271 hire from a very narrow scope of people...”, which establishes cultural conformity 272 exclusive of "outsiders" that might be competent but not sharing the same educational 273 identity.

275 A few interviewees also saw being female as an advantage in certain circumstances, for example by being remembered better among the male-dominated peer group. Three participants believed that the beginning of their careers and their climb on the career ladder had been the most difficult time during their careers due to old beliefs and a highly masculine industry culture, whereas others said that gender-related challenges can actually become worse with aging and increasing career ambitions. The following two quotes illustrate the range of this continuum with respect to being a woman in a maledominant sector:

"You have to endure the first 15 years. But once you get to a senior position, I do not think it is so much of a problem."

"I think it [the greatest challenge] is age and competition. If you're past 40, then I think you begin competing with the guys. And then you start having problems."

Differences were recorded among the interviewees regarding experienced difficulties during their personal career paths. Moreover, the diverse personalities of the interviewed leaders also became visible when reflecting on their personal experiences. Only one leader claimed to have noticed the "Queen Bee phenomenon" (Derks et al. 2011). The woman described the relationships among men to be very brotherly, while women often did not appear to share a similar sisterhood relationship with their female colleagues, which may indicate the need to adapt to the gendered culture. Nonetheless, many respondents highlighted the importance of building a diverse set of competencies and receiving support from their superiors as powerful enablers for their career paths. The most important point was to have someone "...who believes in you...", irrespective of whether it is a male or a female.

299 
300 A more detailed summary of the enablers and challenges regarding career development

301 based on our sample are summarized in Table 3. It should be noted that these factors do 302 not appear in order of any importance ranking. Based on Table 3, several features of 303 gendered culture exist in the Nordic forest industry, which in the context of this study 304 represent challenges for females moving toward leadership positions. These may be 305 generalized for diverse gender identities beyond biological sex. In parallel, several 306 enabling factors that positively promote higher gender equality at the top can also be 307 identified.

Table 3. Observed challenges and enabling factors of female leaders in the Nordic forest industry (modified from Baublyte 2017)

\begin{tabular}{|c|c|}
\hline Observed challenges: & $\begin{array}{l}\text { Characteristics enabling reaching } \\
\text { leadership positions }\end{array}$ \\
\hline $\begin{array}{l}\text { - Existence of masculine networks } \\
\text { and homosocial reproduction } \\
\text { - Not being able to participate in } \\
\text { certain social events due to } \\
\text { gender } \\
\text { - Abandonment of own gender } \\
\text { identity to avoid being } \\
\text { discriminated and stereotyped } \\
\text { - Inconsistency between } \\
\text { characteristics attributed to } \\
\text { leaders and those attributed to } \\
\text { women in general forestry } \\
\text { - A lack of technical form } \\
\text { education background } \\
\text { Social norms regarding } \\
\text { childcare arrangement }\end{array}$ & $\begin{array}{l}\text { - Females aiming for high competence } \\
\text { levels: continuous skill development } \\
\text { and use of cross-functional training, } \\
\text { development of leadership skills } \\
\text { - Females with devotion to tasks, } \\
\text { determination, and awareness of } \\
\text { personal goals and ambitions, and with } \\
\text { readiness to step out of individual } \\
\text { comfort zones and to take chances } \\
\text { - Existing personal-level support } \\
\text { systems } \\
\text { Having a boss supportive of career } \\
\text { development who pushes the employee } \\
\text { to reach higher } \\
\text { Role models exist as an essential aspect } \\
\text { of motivating young females, as well as } \\
\text { modernizing the image of the entire } \\
\text { industry }\end{array}$ \\
\hline
\end{tabular}

\section{Corporate sustainability and the future of the forest industry in the bioeconomy}

315 The perceived gender-related challenges in leadership positions discussed above also 316 provide further insights into strategic business development. The interviewees are not 
317 able to separate their professional and seniority level from their gender, while overall they

318 felt their voices were being heard in the corporate decision-making regarding 319 sustainability issues. They feel they hold sufficient authority and that as leaders they are respected, and their opinions are taken into account. One interviewee underlined that social and environmental sustainability has high personal value, as the following quote elaborates:

"I am in a position where I have influence. And I personally think that sustainability is very important. And I am very much involved in such issues. So I do not think that it is me being a woman, but rather me being in a senior position with an interest in social sustainability issues."

The global role of forest-based bioeconomy in creating a more sustainable future was recognized by all study participants. This was fairly often voiced from a pragmatic perspective regarding the types of products the pulp and paper industry may develop in the future, which may, in part, support more sustainable natural resource-based production and consumption. Replacing plastic and fossil fuels with renewable materials was the most quoted example, and the following quote expresses optimism toward the industry's capability of renewing itself:

"I think there are going to be a lot of new products, to replace plastic for example, also a lot of [development] thinking around the production, what else could be done. We already resemble a circular economy with an integrated pulp mill, and now the question is how to use the side products in a better way."

340 One female leader separated bioeconomy into three production lines: traditional (pulp 341 and paper-based), innovative new products, and the increased reuse of waste and industry 342 side streams. Even though she believed that pulp and paper production is going to be 343 important in the future, she stated that the bioeconomy should focus more on developing 344 new innovations. The third part of the forest bioeconomy, focusing on circularity, may 345 also be crucial for the future of the sector. According to an interviewee, if these parts of 346 the bioeconomy can operate in balance with sustainable forest management, the industry 347 can provide many better solutions for the future of the world. Nonetheless, she concluded 348 with a cautionary note: 

and are intensifying too much too quickly. We need to really consider now how much wood we can really use for our bioeconomy."

353 One interviewee also pointed out that the number of female forest owners is increasing in

354 Finland, as it is in Sweden, which is likely to diversify forest industry firms' roundwood 355 procurement seller-buyer relationships. The diversifying forest ownership structure may 356 also increase demand for non-wood forest products and forest protection services. A more 357 diverse workforce in companies operating both locally and globally would allow leading companies to tap into a broader pool of resources, and to also encourage more intense inter-sector communication, as the following quote illustrates:

"I think, in general, that broader diversity in any kind of dimension has a positive influence. Because you have people with different perspectives, different backgrounds, seeing things in different ways, and that creates [new] dynamics in the industry as such. ... Especially, if you want to look into the future and develop,

367 One interviewee said that forestry could contribute to nearly every SDG set by the UN.

368 Even though the possibilities are endless, companies are practically forced to focus on a few key goals. Replacing fossil fuels and materials, and further developing sustainable forest management solutions were mentioned as crucial avenues towards sustainability. Interviewees also mentioned that reaching the SDGs will inevitably require cooperation between various sectors: companies, various fields, sectors. This is not a one-man show."

375 Lastly, having high corporate standards for social sustainability can be an essential aspect of a more sustainable future, as also envisaged in the emphasis area crossing between SDG 5 and SDG 9. 
381 Our qualitative findings illustrate manifold practical hindrances in what it means to be working as a female top-level leader in the traditional and masculine forest industry, where women are still underrepresented at the management level. The interview results show that the Nordic forest industry is still considered a traditional and masculine field of business, as also noted in previous literature (Lidestav and Sjölander 2007; Vainio and Paloniemi 2013). However, the ability of the interviewed female leaders to succeed in their careers despite gendered culture-related barriers demonstrates that the forest sector is moving ahead towards higher gender diversity. Despite this indication, it must be remembered that this is a highly exclusive and extremely small group of female leaders, as we identified a total of 32 women in top management teams or equivalent leadership roles of business lines.

393 With the limited amount of evidence gathered through our interviews with 10 managers,

394 we cannot formulate definitive conclusions on the state of gender-related challenges in 395 the Nordic forest sector. It is also not possible to depict the state of reported phenomena 396 beyond the sample, such as the need to mimic the behavior of male peers (Hoyt and 397 Murphy 2016) or even the lack of empathy for female peers (Derks et al. 2011). 398 Moreover, certain issues may be so painful that the interviewees did not consider even 399 the anonymous interview situations confidential enough to bring them to light, thus 400 fostering conformity with a culture of silence needed for "climbing the ladder" in the 401 industry (Johansson et al. 2018). For example, tokenism, the practice of hiring women 402 merely to improve a company's gender ratio did not emerge from the interviews, even 403 though it appears relevant in previous literature on gender diversity (Bear et al. 2010). 404 Notably, while the interviewed women on the one hand acknowledge the role of gender 405 diversity in transforming the industry, on the other hand they identify such transformation 406 as still conforming to masculine norms. Holmgren and Arora-Jonsson (2015) observed a 407 similar phenomenon in the context of Swedish forest policy, where the explicitly 408 articulated aim is to change women from being "inactive" and "underpresented" rather 409 than changing the underlying structures, which make them marginalized in the forest 410 sector. According to them, the dominance of economic values (competitiveness, 411 economic growth, individualism, faith in markets) over sustainability and responsibility 
412 instill the renewal of the forest sector toward improved climate mitigation practices and 413 gender equality (Holmgren and Arora-Jonsson 2015).

414

415 The results from our study have concurrently built a positive picture of the active 416 recognition of sustainability issues at the top leadership level. This impacts the Nordic

417 forest industry by increasing the awareness level concerning the importance of corporate 418 sustainability and the importance of the question of how the forest industry could 419 potentially contribute to solving global sustainability challenges. The interviewed female 420 leaders unanimously stated that their influence on industry sustainability agenda comes 421 from being in a senior position. This warrants studying the same topics among a 422 comparable sample of male leaders, to assess whether gender-specific influences to 423 sustainability orientation can be established or not. In general, we have very limited 424 understanding concerning the role of the actual people driving the change to the 425 bioeconomy (Hansen et al. 2016). We have limited understanding of the knowledge and 426 power structures these people create, and how these structures are related to gender or 427 diversity.

429 Nonetheless, the ability of Nordic forest companies to adapt to future needs will obviously 430 require more diverse company culture, which is not solely gender based and is fostered 431 at all organizational levels. Replacing fossils fuels, plastic, metal, and cotton with 432 renewable bio-based materials will require the intensified use of forest resources, but the 433 challenge is accomplishing this without compromising sustainability in resource use. 434 Enhancing circular economy aspects, suggested by one of the interviewees, could provide 435 solutions to this (Ciccarese et al. 2014; Bezama 2016; Vis et al. 2016). The respondents 436 in our study also remarked that the future of the forest sector relies on a shift from 437 traditional (pulp and paper) to more innovative products.

439 As also emphasized by Kleinschmit et al. (2014), the bioeconomy concept has developed 440 to include a great variety of agendas and ambitions, implying that challenges and 441 opportunities may cause the borders of the traditional forest sector to become blurred. 442 The next significant goal for forest companies appears to be modernizing the industry's 443 image. An aging workforce and inability to attract young talent create a barrier for further 444 industrial development. Playing an important role in a sustainable future, the forestry 
industry must rethink its old concepts and become a part of the modern and urbanized world. Focusing on the bioeconomy and innovativeness of future solutions, the sector can (and should) interest and attract young talents (Hodge et al. 2017; Lawrence et al. 2017).

\section{Conclusions and future research}

451 Our exploratory study investigated perceptions of female leaders in the Nordic forest 452 industry on gendered culture in the workplace, and on their role in the strategic decision453 making process toward corporate sustainability and the future of forest industry in the 454 bioeconomy. The Nordic forest industry still appears to be a traditional and masculine 455 field of business. A more diverse company culture at all organizational levels, not just 456 gender based, has been called for to foster the ability of the Nordic forest industry to adapt 457 to strategic renewal into the bioeconomy. Higher diversity at the top management level 458 represents one under-recognized opportunity, which may allow the industry to grow and evolve into an even more important player globally, to better meet diverse customer expectations, and to earn the social license to operate both at local and global levels. However, having no active diversity management policy can create challenges in the work climate and job satisfaction (see e.g. Vinnicombe and Singht 2002; Aalto et al. 2014).

Many areas still require investigation from a gender-specific research perspective. Due to the small number of potential respondents in the context of the Nordic forest sector, pursuing face-to-face and longer interviews may be worthwhile. Broader samples could otherwise extend to women working in middle management or in small- and mediumscale forest companies, as well as the top management level in expert roles. This could bring new and more comprehensive insights concerning the role of women empowerment as a way of increasing the inclusiveness and social sustainability of Nordic societies.

473 Collecting paired reference data on male leaders from a similar management level would 474 also be of interest, to reach a more comprehensive and comparative assessment on top 475 management perspectives concerning the commitment to sustainability and other core 476 issues - such as the bioeconomy - around industry renewal opportunities and challenges. 
478 Expanding the analyses to other areas beyond the Nordic countries would be useful in 479 discerning between culture-specific and more universal aspects. Comparative 480 assessments can also be performed with other masculine industries, such as metal industry 481 or engineering and consulting, which have undergone changes in gender diversity. This 482 would allow the forest industry to learn from best practices implemented elsewhere.

484 At the practical level, a scope to eliminate discriminations and stereotypes still appears to 485 exist, and company-level gender diversity and awareness programs should be developed 486 further to reach this outcome. Educating employees about the challenges of underrepresented employee groups and the underlying causes of these issues could improve the general awareness in the subject matter (Johansson et al. 2018). Having more clear and concrete diversity goals at different levels of the company, rather than one for leadership teams and one for more general purposes, could allow companies in the Nordic forest industry to identify problem areas and focus on solving the most critical ones.

\section{Acknowledgments}

494 We are grateful to the funding bodies of the Academy of Finland (Grants \#307480 and \#315912) and the Jenny ja Antti Wihuri foundation. We wish to warmly thank the interviewees that participated in the data collection.

\section{References}

Aalto, A.M., Heponiemi, T., Väänänen, A., Bergbom, B., Sinervo, T., Elovainio, M., 2014. Is working in culturally diverse working environment associated with physicians' work-related well-being? A cross-sectional survey study among Finnish physicians. Health Policy (New. York). https://doi.org/10.1016/j.healthpol.2014.02.006

506 Adams, R.B., de Haan, J., Terjesen, S., van Ees, H., 2015. Board diversity: Moving the 
509 Appelstrand, M., Lidestav, G., 2015. Women entrepreneurship - a shortcut to a more

510 competitive and equal forestry sector? Scand. J. For. Res.

511 https://doi.org/10.1080/02827581.2015.1011408

512

513 Bayblyte, G. 2017. Gender Diversity in Swedish and Finnish Forest Industry Companies:

514 Challenges and Enablers. Master's thesis, University of Helsinki. 48 p.

515

516 Bear, S., Rahman, N., Post, C., 2010. The Impact of Board Diversity and Gender

517 Composition on Corporate Social Responsibility and Firm Reputation. J. Bus. Ethics.

518 https://doi.org/10.1007/s10551-010-0505-2

519

520 Berry, J.M., 2002. Validity and reliability issues in elite interviewing, in: PS - Political

521 Science and Politics. https://doi.org/10.1017/S1049096502001166

522

523 Bennich, T., Belyazid, S., 2017. The route to sustainability-prospects and challenges of

524 the bio-based economy. Sustain. doi:10.3390/su9060887

525

526 Bezama, A., 2016. Let us discuss how cascading can help implement the circular

527 economy and the bio-economy strategies. Waste Manag. Res.

528 https://doi.org/10.1177/0734242X16657973

529

530 Blau, F.D., Kahn, L.M., 2017. The Gender Wage Gap: Extent, Trends, and Explanations.

531 J. Econ. Lit. 55, 789-865. https://doi.org/10.1257/jel.20160995

532

533 Bugge, M.M., Hansen, T., Klitkou, A., 2016. What is the bioeconomy? A review of the

534 literature. Sustain. https://doi.org/10.3390/su8070691

535

536 Ciccarese, L., Mattsson, A., Pettenella, D., 2012. Ecosystem services from forest

537 restoration: Thinking ahead. New For. https://doi.org/10.1007/s11056-012-9350-8 
539 D'Amato, D., Korhonen, J., Toppinen, A. 2019. Circular, Green, and Bio economy: how

540 do companies in land-use intensive sectors align with sustainability concepts? Ecological

541 Economics 158: 116-133.

542

543 D'Amato, D., Veijonaho, S., Toppinen, A. 2018. Towards Sustainability? Forest544 based circular bioeconomy business models in Finnish SME. Forest Policy and 545 Economics (In Press). https://doi.org/10.1016/j.forpol.2018.12.004

547 D’Amato, D., Wan, M., Li, N., Rekola, M., Toppinen, A., 2016. Managerial Views of 548 Corporate Impacts and Dependencies on Ecosystem Services: A Case of International 549 and Domestic Forestry Companies in China. In press, Journal of Business Ethics, 11-8. 550 https://doi.org/10.1007/s10551-016-3169-8

552 Derks, B., Ellemers, N., van Laar, C., de Groot, K., 2011. Do sexist organizational 553 cultures create the Queen Bee? Br. J. Soc. Psychol. 554 https://doi.org/10.1348/014466610X525280

555

556 Gummesson, E., 1991. Qualitative methods in management research. Sage Publications, 557 London.

558

559 Hansen, E. 2016. Responding to the bioeconomy: Business model innovation in the forest 560 sector. In Kutnar, A., and Muthu, S. (eds): Environmental Impacts of Traditional and 561 Innovative Forest-Based Bioproducts. Springer, Singapore. pp. 227-248.

562

563 Hansen, E., Conroy, K., Toppinen, A., Bull, L., Kutnar, A., Panwar, R., 2016. Does 564 gender diversity in forest sector companies matter? Can. J. For. Res. 565 https://doi.org/10.1139/cjfr-2016-0040

567 Hodge, D., Brukas, V., Giurca, A., 2017. Forests in a bioeconomy: bridge, boundary or 568 divide? Scand. J. For. 569 https://doi.org/10.1080/02827581.2017.1315833 
571 Holmgren, S., Arora-Jonsson, S., 2016. The Forest Kingdom and values: Climate change

572 and gender equality in a contested forest policy context, in: Gender and Forests: Climate

573 Change, Tenure, Value Chains and Emerging Issues.

574 https://doi.org/10.4324/9781315666624

575

576 Hoyt, C.L., Murphy, S.E., 2016. Managing to clear the air: Stereotype threat, Women,

577 And leadership. Leadersh. Q. https://doi.org/10.1016/j.leaqua.2015.11.002

578

579 Johansson, M., Ringblom, L., 2017. The Business Case of Gender Equality in Swedish

580 Forestry and Mining - Restricting or Enabling Organizational Change. Gender, Work

581 Organ. https://doi.org/10.1111/gwao.12187

582

583 Johansson, M., Johansson, K., Andersson, E., 2018. \#Metoo in the Swedish forest sector:

584 testimonies from harassed women on sexualised forms of male control. Scand. J. For.

585 Res. https://doi.org/10.1080/02827581.2018.1474248

586

587 Kakabadse, N.K., Figueira, C., Nicolopoulou, K., Hong Yang, J., Kakabadse, A.P.,

588 Özbilgin, M.F., 2015. Gender diversity and board performance: Women's experiences

589 and perspectives. Hum. Resour. Manage. https://doi.org/10.1002/hrm.21694

590

591 Kleinschmit, D., Lindstad, B.H., Thorsen, B.J., Toppinen, A., Roos, A., Baardsen, S.,

592 2014. Shades of green: A social scientific view on bioeconomy in the forest sector. Scand.

593 J. For. Res. https://doi.org/10.1080/02827581.2014.921722

594

595 Korhonen, J., Hurmekoski, E., Hansen, E., Toppinen, A., 2018. Firm-level 596 competitiveness in the forest industries: review and research implications in the context

597 of bioeconomy strategies. Can. J. For. Res. https://doi.org/10.1139/cjfr-2017-0219

599 Lawrence, A., Spinelli, R., Toppinen, A., Salo, E. 2017. What are the implications of

600 the bioeconomy for forest-related jobs? In: Winkel, G. (ed.) Towards a sustainable

601 bioeconomy - a - assessment and the way forward, EFI What Science Can Tell Us 8,

602 pp. 108-117.

603 
604 Li, N., Toppinen, A., 2011. Corporate responsibility and sustainable competitive 605 advantage in forest-based industry: Complementary or conflicting goals? For. Policy 606 Econ. https://doi.org/10.1016/j.forpol.2010.06.002

607

608 Lidestav, G., Sjölander, A.E., 2007. Gender and forestry: A critical discourse analysis of 609 forestry professions in Sweden. Scand. J. For. Res. 610 https://doi.org/10.1080/02827580701504928

611

612 Ollikainen, M., 2014. Forestry in bioeconomy - smart green growth for the humankind.

613 Scand. J. For. Res. https://doi.org/10.1080/02827581.2014.926392

614

615 Perrault, E., 2015. Why Does Board Gender Diversity Matter and How Do We Get There?

616 The Role of Shareholder Activism in Deinstitutionalizing Old Boys’ Networks. J. Bus.

617 Ethics. https://doi.org/10.1007/s10551-014-2092-0

618

619 Post, C., Rahman, N., Rubow, E., 2011. Green governance: Boards of directors' 620 composition and environmental corporate social responsibility. Bus. Soc. 621 https://doi.org/10.1177/0007650310394642

622

623 Pfau, S.F., Hagens, J.E., Dankbaar, B., Smits, A.J.M., 2014. Visions of sustainability in 624 bioeconomy research. Sustain. https://doi.org/10.3390/su6031222

625

626 Pätäri, S., Tuppura, A., Toppinen, A., Korhonen, J., 2016. Global sustainability 627 megaforces in shaping the future of the European pulp and paper industry towards a 628 bioeconomy. For. Policy Econ. https://doi.org/10.1016/j.forpol.2015.10.009 629

630 Roos, A., Stendahl, M., 2016. Emerging bioeconomy and the forest sector. In: Panwar, 631 R. et al, (eds.). Forests, Business and Sustainability. Routledge, New York. 632

633 Umaerus, P., Lidestav, G., Eriksson, L.O., Högvall Nordin, M., 2013. Gendered business 634 activities in family farm forestry: From round wood delivery to health service. Scand. J. 635 For. Res. https://doi.org/10.1080/02827581.2013.793385 636 
637 Wolfslehner B., Linser S., Pülzl H., Bastrup-Birk A., Camia A., Marchetti M. 2016.

638 Forest bioeconomy - a new role for sustainability indicators. From Science to Policy 4, 639 32, European Forest Institute.

640

641 Vainio, A., Paloniemi, R., 2013. Adapting to the gender order: Voluntary conservation 642 by forest owners in Finland. Land use policy. 643 https://doi.org/10.1016/j.landusepol.2013.05.017

644 Vinnicombe, S., Singh, V., 2002. Women-only management training: An essential part 645 of women's leadership development. J. Chang. Manag 3, 294-306.

646 https://doi.org/10.1080/714023846

647

648 Appendix 1. Interview questions

649 GENDER \& FOREST INDUSTRY

650 1. How would you describe the general atmosphere within your company with respect

651 to females in the workforce? (Has this changed during your time at the company?)

652 2. How would you describe the general atmosphere within the industry with respect to 653 females in the workplace? (Has this changed during your career?)

\section{CAREER PATH}

655 3. What do you think were the main three factors that helped you attain a leader's 656 position in this field?

657 4. What do you consider to be the three largest obstacles to overcome to advance to this 658 position?

659 5. What do you currently see as the most challenging issue in being a female leader in 660 the forestry sector?

661 IMPACT 
662 6. How do you think your presence as a female leader impacts the financial,

663 environmental, and social performance of your company?

664 7. As a female leader, do you think you can influence the strategic planning/decision-

665 making process in relation to corporate sustainability? In what way?

666 8. From your perspective, what do you see as the primary benefits to a forest sector

667 company in having females in top leadership?

668 FUTURE

669 9. What would make the sector a more attractive place to work for female leaders?

670 10. What advice would you give to young females entering the industry?

671 11. In your opinion, how can the forest sector contribute to the Sustainable

672 Development Goals (timeframe: towards 2030)?

673 12. What is the future of the forest sector in the bioeconomy (towards 2030)? Please

674 describe in 2-3 sentences. 